Habib Jalilian ${ }^{1,2}$, Mohammad Zakaria Pezeshki ${ }^{3}$, Leila Torkzadeh4, Elnaz Javanshir ${ }^{5}$, Ahmad Moradi ${ }^{6}$, Rahim Khodayari-Zarnaq ${ }^{1,7}$

${ }^{1}$ Iranian Center of Excellence in Health Management, Department of Health Services Management, School of Management and Medical Informatics, Tabriz University of Medical Sciences, Tabriz, Iran

${ }^{2}$ Student Research Committee, Tabriz University of Medical Sciences, Tabriz, Iran

${ }^{3}$ Social Determinants of Health Research Center, Department of Community and Family Medicine, Tabriz Medical School, Tabriz University of Medical Sciences, Tabriz, Iran

${ }^{4}$ Iranian Center of Excellence in Health Management, Department of Health Services Management, School of Management and Medical Informatics, Tabriz University of Medical Sciences, Tabriz, Iran

${ }^{5}$ Cardiovascular Research Centre, Tabriz University of Medical Sciences, Tabriz, Iran

${ }^{6}$ Department of Public Health, Shoushtar Faculty of Medical Sciences, Shoushtar, Iran

${ }^{7}$ Tabriz Health Services Management Research Center, Health Management and Safety Promotion Research Institute, Tabriz University

of Medical Sciences, Tabriz, Iran

\title{
Health care seeking behaviors in type 2 diabetic patients in East Azerbaijan
}

\section{ABSTRACT}

Background. Timely and effective use of health care services is essential to delay or prevent complications and reduce the burden of diabetes. Positive health care seeking behaviors can improve diabetes control and, as a result, reduce the incidence of the complications. So, this study aimed to investigate the status of health care seeking behaviors and affecting factors in type 2 diabetic patients.

Materials and methods. This was a cross-sectional study. There were 1139 patients with type 2 diabetes aged $>18$ years selected who referred to educational hospitals, Endocrinologist office, primary health care centers, and Clinics. Data collected using a researchermade questionnaire and analyzed using SPSS software version 22.

Results. $36.3 \%$ of diabetic patients initially referred to a physician in the event of illness symptoms, and $70.7 \%$ of patients referred to a physician in case of exacerbating of disease symptoms. $58.4 \%$ of patients preferred to consult a specialist directly. 78.85 of patients reported that they had referred to a physician on a regular basis and $59.9 \%$ of patients followed up their

Address for correspondence:

Rahim Khodayari-Zarnaq

Phone: 0098-9147864767

e-mail: Rahimzarnagh@gmail.com

Clinical Diabetology 2019, 8, 6, 292-302

DOI: $10.5603 /$ DK.2019.0031

Received: 24.07.2019

Accepted: 09.12.2019 treatment process on a regular basis. The physician was the main source of information for the majority of patients. Income, education and health insurance status, disease severity, chronicity of DM, the history of hospitalization due to DM were the affecting factors on health care seeking behaviors ( $p<0.05$ ).

Conclusion. Most of the diabetics often did not follow the official structure of health care providing to manage their illness, and despite the referral system and family practitioner program more than half of the patients went directly to the specialist physician's office. Factors related to the patient (an income and education status), disease characteristics (disease severity, chronicity of DM and the history of hospitalization due to DM) and health care system factors (type of the basic insurance and supplementary insurance status) affect the health care seeking behaviors. (Clin Diabetol 2019; 8, 6: 292-302)

Key words: health-seeking behaviors, healthcare seeking behaviors, help-seeking behavior, information seeking behavior, treatment seeking behavior, type 2 diabetes mellitus

\section{Introduction}

In order to delay or prevent complications, diabetic patients have to adopt certain lifestyle changes and comply with drug therapy. These measures need to be preserved for long-term, and so, sustained follow-ups 
are necessary [1]. Also, diabetes management includes multiple health care providers $[2,3]$.

Timely and effective use of health care services, especially primary health care, is essential to reduce the burden of diabetes [4]. Effective utilization of health care services is affected by health care seeking behaviors. Health seeking behavior (HSB) has been defined as any activity or inaction undertaken by individuals who perceive themselves to have a health problem or to be ill for the purpose of finding an appropriate remedy [5]. It is well established that HSB is influenced by the manifestation of symptoms $[1,6]$. Most patients with diabetes are asymptomatic at the time of initial diagnosis; so, no feeling they need to get health care and disease denial is a pivotal barrier in disease management [7]. For diabetes, there is a tendency for patients to delay or ignore health care measures until the complications become evident [8].

Positive health-seeking behavior (i.e., the early recognition of symptoms, presentation to health facilities, and compliance with effective treatment) could improve diabetes control and as a result, reduce the incidence of the complications caused by this devastating disease [9] and ultimately could improve the quality of life of patients with diabetes mellitus [10].

Moreover, understanding community patterns of health care-seeking behaviors, which in the society are the first points of care, would improve public health practice in the society [11] and it is important so as to develop proper health management strategies [12]. The knowledge regarding health-seeking behavior can assist health policymakers in order to identify referral patterns, affecting factors, barriers to access and use of services, and implement appropriate interventions to guide patients in the right way to receive services and remove barriers to the use of services $[13,14]$. Since there are few published studies dealing with the health-seeking behaviors in the diabetic patients in Iran, the aim of this study is to describe the health-seeking behavior of patients with type 2 diabetes mellitus and its affecting factors.

\section{Health care system in Iran}

The health system structure in Iran consists of two sectors. The public sector structured based on the threelevel referral system (primary, secondary, and tertiary health services) and family practitioner. Over the last two decades, the emphasis of the government on primary health care has made the public sector the main provider of primary health care services in the whole country. In addition, the public sector provides a notable part of secondary and tertiary health services in the provinces of Iran. The private sector mainly focuses on secondary and tertiary health care in urban areas and it benefits from a good deal of prestige. Also, there are many nongovernmental organizations (NGOs) active in health issues in Iran, mainly active in special fields like children with cancer, breast cancer, diabetes, thalassemia, and so on [15-17].

\section{Materials and methods}

Study design, sample size, and sampling

This was a cross-sectional study. The statistical population included all patients with type 2 diabetes aged $>18$ years, without having physical and mental disabilities, who referred to educational hospitals(Imam Reza and Sina's educational and therapeutic centers and Asad Abadi clinic in Tabriz, Iran), Endocrinologist office, health centers and Sheykh Al-Raees Clinic. The sample size includes 1200 diabetic patients. Sampling was performed in Sequential Sampling Method.

\section{Data collection tools}

Data was collected using a researcher-made questionnaire. The questionnaire consisted of three sections. The first section contained demographic characteristics and socioeconomic status. The second section contained disease-related variables of diabetic patients. The third section contained the questions pertaining to the justification for health care seeking behaviors in patients with type 2 diabetes. The questionnaire was designed based on literature review and reviewing the models and theories related to the health care seeking behaviors, reviewing existing questionnaires on healthseeking behaviors especially questionnaires related to health care seeking behavior in diabetic patients and also interviews with experts. At the next step, the Content Validity Ratio (CVR) and Content Validity Index (CVI) were used for quantitative assessment of the content validity. The scores for the CVI and CVR were 0.9 and 0.76 , respectively, in Table 1 . The total number of experts to assess the validity of the questionnaire was 40 people.

\section{Data collection}

After approving the study protocol in the Ethics Committee of the University, the questionnaires were given to the participants by referring to the treatment centers. Moreover, the required explanations were given to the patients about the objectives of the study and how to complete the questionnaire. For illiterate people, the questionnaire was read by an interviewer to the participants while they were completing their questionnaire. 
Table 1. The scores of Content Validity Ratio (CVR) and Content Validity Index (CVI)

\begin{tabular}{|c|c|c|c|}
\hline Number & Questions related to health care seeking behaviors & CVI & CVR \\
\hline 1 & What is the first action when you have symptoms? & 0.89 & 0.9 \\
\hline 2 & In the case of the manifestation of illness symptoms, who would you rather consult with first? & 0.96 & 0.7 \\
\hline 3 & $\begin{array}{l}\text { When you get sick, Which health care provider do you refer in order to receive health services? } \\
\text { (Public or private) }\end{array}$ & 0.9 & 0.55 \\
\hline 4 & $\begin{array}{l}\text { When you get sick, which health care provider centers do you refer? (In terms of the referral } \\
\text { level of the service providers) }\end{array}$ & 0.8 & 0.65 \\
\hline 5 & $\begin{array}{l}\text { Under which circumstances do you visit a doctor? (On a regular basis and periodically — in the } \\
\text { occurrence of disease symptoms - in case of exacerbate of disease symptoms) }\end{array}$ & 0.87 & 0.8 \\
\hline 6 & How often do you visit your doctor? & 0.97 & 0.75 \\
\hline \multirow[t]{2}{*}{7} & $\begin{array}{l}\text { From what sources do you get the required information for treatment and how you control } \\
\text { diabetes? (Mark the most important resource/just one option) }\end{array}$ & 0.94 & 1.00 \\
\hline & Total score & 0.9 & 0.76 \\
\hline
\end{tabular}

\section{Data analysis}

Data were analyzed using SPSS 22. Frequencies, percent, mean and SD was calculated for the variables. Chi-square test was used to assess the association between the demographic, socioeconomic and disease-related variables and health-seeking behaviors.

\section{Results}

Characteristics of the study population are shown in Table 2. 1139 questionnaires out of 1200 distributed questionnaires were included in the final analysis, and 60 questionnaires were excluded due to huge missing data. $66.3 \%$ of the patients were women. The mean \pm SD of age, disease duration and body mass index (BMI) of patients were $56.93 \pm 13.34$ years, $9.06 \pm 7.12$ years and $28.37 \pm 5.27$, respectively. $41.5 \%$ of the patients were illiterate. The type of current treatment of most diabetic patients (54.3\%) was oral agents. $30.2 \%$ of patients had a history of hospitalization due to complications of diabetes during the past year. $76.1 \%$ of patients had at least one comorbidity or complication (Table 2).

In the event of illness symptoms, the majority of patients (36.3\%) were referred to a physician. However, a substantial percentage of patients changed their behavior or did self-medication.70.7\% of patients reported they referred to a physician in case of exacerbating of disease symptoms and complications. In the case of manifesting or exacerbating the symptoms of the disease, $58.4 \%$ of patients reported they preferred to consult a specialist physician. Approximately more than half of the patients $(50.9 \%)$ referred to public hospitals or university clinics. 78.85 of patients reported they referred to a physician on a regular basis to manage their disease in the event of illness and
$59.9 \%$ of patients followed up their treatment process on a regular basis. $51.6 \%$ of patients visited a general practitioner every three months. The physician was the most frequent source of required information for most patients (65.7\%) (Table 3).

As can be seen from Table 4, income status, severity of illness, chronicity of DM and the history of hospitalization due to complications of diabetes during the past year were the affecting factors on the most health-seeking behaviors, and this association was statistically significant $(p<0.05$ ). The type of basic insurance and supplementary insurance status were significantly associated with the follow-up pattern and the type of health center receiving the services ( $p$ $<0.05$ ). Education status was significantly associated with the first care provider for consulting, the type of health center to receive services $(p<0.05)$.

In this study, patients with lower income were more likely to go to a physician in the event of illness symptoms, whilst those with higher income were more likely to do self-medication or change their behavior. In the event of illness symptoms, patients living in urban areas were more likely to refer to a physician and change their behavior, whereas those living in rural areas were more likely to consult family members, friends, relatives, and do self-medication. Patients with no history of hospitalization were more likely to refer to a physician, while those with a history of hospitalization were more likely to do self-medication.

Patients with higher income and education reported that they initially refer to a physician in the event of illness symptoms, whereas those with lower income and education level reported that they initially refer to primary health care providers. Patients with longer disease duration and history of hospitalization, 
Table 2. Demographic and clinical profile

\begin{tabular}{|c|c|c|c|}
\hline Variable & Mood & Frequency & Percent \\
\hline \multirow[t]{2}{*}{ Gender } & Male & 384 & 33.7 \\
\hline & Female & 755 & 66.3 \\
\hline \multirow[t]{3}{*}{ Age } & $<40$ & 127 & 11.2 \\
\hline & $40-60$ & 527 & 46.3 \\
\hline & $>60$ & 485 & 42.6 \\
\hline \multirow[t]{2}{*}{ Income status } & $<10$ million Rials & 397 & 52.5 \\
\hline & $>10$ million Rials & 359 & 47.5 \\
\hline \multirow[t]{4}{*}{ Education status } & Illiterate & 473 & 41.5 \\
\hline & Reading and writing ability & 407 & 35.7 \\
\hline & Diploma & 195 & 17.1 \\
\hline & Academic education & 64 & 5.6 \\
\hline \multirow[t]{2}{*}{ Type of basic health insurance } & Social security & 707 & 64.4 \\
\hline & Iranian health insurance & 391 & 35.6 \\
\hline \multirow[t]{2}{*}{ Supplementary health insurance status } & Yes & 430 & 39.1 \\
\hline & No & 669 & 60.9 \\
\hline \multirow[t]{2}{*}{ Habitation status } & Rural area & 135 & 11.9 \\
\hline & Urban area & 1003 & 88.1 \\
\hline \multirow[t]{3}{*}{ Disease duration } & $<5$ year & 421 & 37.1 \\
\hline & 5 to 10 years & 260 & 22.9 \\
\hline & $>10$ years & 455 & 40.1 \\
\hline \multirow[t]{3}{*}{ Type of current treatment } & Oral pills & 619 & 54.3 \\
\hline & Insulin & 449 & 39.4 \\
\hline & $\begin{array}{l}\text { Change in lifestyle (change in diet } \\
\text { and physical activity) }\end{array}$ & 71 & 6.2 \\
\hline \multirow[t]{2}{*}{ Presence of co-morbidity or complications } & Yes & 867 & 76.1 \\
\hline & No & 272 & 23.9 \\
\hline The history of hospitalization due to complications & Yes & 344 & 30.2 \\
\hline of diabetes during the past year & No & 795 & 69.8 \\
\hline
\end{tabular}

those who rated their disease severity as severe, those with diabetes complications and patients whose main treatment strategy was taking insulin were more likely to refer to a physician.

Patients with higher incomes and education, those who are living in urban areas, those with the social security basic health insurance and those who have supplementary insurance, those with longer disease duration and the history of hospitalization due to complications of DM and those who rated their disease severity as low were more likely to refer to tertiary level of heath care providers, such as special hospital, private hospitals and private doctor's office. Patients whose current treatment was based on change in the lifestyle were more likely to refer to primary health care providers.

Patients with higher income and education, those living in urban areas, those with social security insurance and supplementary insurance, those with longer disease duration and those who rated their disease severity as severe were more likely to refer to private centers for receiving services. Also, patients who had no history of hospitalization due to diabetes complications during the past year were more likely to go to private centers; Table 5.

Moreover, older patients, those living in urban areas, those with the social security insurance and supplementary insurance coverage, those with longer disease duration, and patients with no history of hospitalization were more likely to refer to a physician on a regular basis; Table 6 .

\section{Discussion}

This study examines the health care seeking behaviors and its affecting factors in patients with type 2 diabetes. Despite the implementation of family physician program, just a few percentages of individuals chose to consult a family physician in the event of 
Table 3. Health care seeking behaviors profile

\begin{tabular}{|c|c|c|c|}
\hline Questions & Options & Frequency & $\%$ \\
\hline \multirow[t]{4}{*}{ The first action in the event of illness symptoms } & Refer to a doctor & 413 & 36.3 \\
\hline & $\begin{array}{l}\text { Behavior change (change diet } \\
\text { or/and physical activity level) }\end{array}$ & 327 & 28.7 \\
\hline & Self-medication & 325 & 28.6 \\
\hline & $\begin{array}{l}\text { Consult and get tips from } \\
\text { family members, friends and } \\
\text { other people around you }\end{array}$ & 73 & 6.4 \\
\hline \multirow[t]{3}{*}{ The first action in case of exacerbating of symptoms } & Refer to a doctor & 805 & 70.7 \\
\hline & $\begin{array}{l}\text { Behavior change (diet change } \\
\text { and physical activity level) }\end{array}$ & 306 & 26.9 \\
\hline & Changing physician & 28 & 2.5 \\
\hline \multirow[t]{3}{*}{$\begin{array}{l}\text { The first care provider to consult in case of manifest- } \\
\text { ing or exacerbating the symptoms of the disease }\end{array}$} & $\begin{array}{l}\text { Primary health care providers } \\
\text { such as Behvarz and health watch }\end{array}$ & 103 & 9.1 \\
\hline & Family/general practitioner & 371 & 32.6 \\
\hline & Specialist & 665 & 58.4 \\
\hline \multirow[t]{3}{*}{$\begin{array}{l}\text { The type of health care center to visit and receive the } \\
\text { service }\end{array}$} & $\begin{array}{l}\text { Primary health care centers } \\
\text { (health house and health center) }\end{array}$ & 211 & 18.5 \\
\hline & General hospitals & 580 & 50.9 \\
\hline & $\begin{array}{l}\text { Special hospital, private hospital } \\
\text { or private doctor's office }\end{array}$ & 348 & 30.6 \\
\hline The type of health care center to visit and receive the & Public health centers & 821 & 72.1 \\
\hline service & Private health centers & 318 & 27.9 \\
\hline Regular referring to the doctor in order to better & Yes & 896 & 78.8 \\
\hline manage the disease & No & 241 & 21.2 \\
\hline \multirow[t]{3}{*}{ Follow-up pattern (How do you see your doctor?) } & Asymptomatic/on a regular basis & 682 & 59.9 \\
\hline & In the event of symptoms & 276 & 24.2 \\
\hline & $\begin{array}{l}\text { In the case of exacerbation of } \\
\text { the symptoms or complications } \\
\text { of the disease }\end{array}$ & 181 & 15.9 \\
\hline Follow-up pattern & Once a week & 49 & 4.3 \\
\hline \multirow[t]{6}{*}{ (How often do you visit your doctor?) } & Once every two weeks & 22 & 1.9 \\
\hline & Monthly & 136 & 11.9 \\
\hline & Every three months & 588 & 51.6 \\
\hline & Once every six months & 114 & 10.0 \\
\hline & Once every year & 32 & 2.8 \\
\hline & If needed & 198 & 17.4 \\
\hline The most frequently used information source & Family members and friends & 243 & 21.5 \\
\hline \multirow[t]{3}{*}{ for disease management } & Physician & 745 & 65.9 \\
\hline & $\begin{array}{l}\text { Radio and TV programs, } \\
\text { electronic database, blogs, } \\
\text { websites, health portals, mobile } \\
\text { applications, social networks }\end{array}$ & 129 & 11.4 \\
\hline & Join the Diabetes Associations & 13 & 1.2 \\
\hline
\end{tabular}

illness symptoms. By contrast, a greater percentage of patients preferred to go to specialist physicians directly by bypassing the referral system. This issue disrupts the integrity and continuity of care addition to overuse the specialists' services and imposing additional costs on the health care system. This is because basic insurances have not played their role properly, and they reimburse the cost of self-referral to specialist doctors. In other 
Table 4. Factors affecting health care seeking behaviors

\begin{tabular}{|c|c|c|c|c|c|c|c|c|c|c|}
\hline \multirow[t]{2}{*}{ Variables } & \multicolumn{2}{|c|}{$\begin{array}{l}\text { The first action in } \\
\text { case of the } \\
\text { occurrence } \\
\text { of disease } \\
\text { symptoms }\end{array}$} & \multicolumn{2}{|c|}{$\begin{array}{l}\text { The first care } \\
\text { provider to consult } \\
\text { in case of incidence } \\
\text { or exacerbation } \\
\text { of the symptoms } \\
\text { of the disease }\end{array}$} & \multicolumn{2}{|c|}{$\begin{array}{l}\text { The type of health } \\
\text { care center to } \\
\text { receive the services } \\
\text { (primary, secondary } \\
\text { or tertiary level) }\end{array}$} & \multicolumn{2}{|c|}{$\begin{array}{l}\text { The type of health } \\
\text { care center to } \\
\text { receive the services } \\
\text { (public or private) }\end{array}$} & \multicolumn{2}{|c|}{$\begin{array}{l}\text { Follow-up } \\
\text { pattern }\end{array}$} \\
\hline & $\chi^{2}$ & $P$ value & $\chi^{2}$ & $P$ value & $\chi^{2}$ & $P$ value & $\chi^{2}$ & $P$ value & $\chi^{2}$ & $P$ value \\
\hline Gender & 3.95 & 0.26 & 3.31 & 0.19 & 2.31 & 0.31 & 1.18 & 0.27 & 2.81 & 0.24 \\
\hline Age groups & 2.96 & 0.81 & 5.21 & 0.26 & 5.25 & 0.26 & 5.20 & 0.074 & 13.09 & 0.01 \\
\hline Income status & 23.27 & $<0.0001$ & 8.47 & 0.01 & 61.09 & $<0.0001$ & 27.03 & $<0.0001$ & 1.98 & 0.37 \\
\hline Education status & 14.54 & 0.10 & 13.61 & 0.03 & 55.69 & $<0.0001$ & 35.15 & $<0.0001$ & 7.49 & 0.27 \\
\hline Habitant status & 18.82 & $<0.0001$ & 0.98 & 0.61 & 24.88 & $<0.0001$ & 13.11 & $<0.0001$ & 8.6 & 0.01 \\
\hline $\begin{array}{l}\text { Type of basic health } \\
\text { insurance }\end{array}$ & 3.704 & 0.29 & 0.41 & 0.81 & 12.70 & 0.002 & 7.61 & 0.006 & 16.44 & $<0.0001$ \\
\hline $\begin{array}{l}\text { Supplementary health } \\
\text { insurance status }\end{array}$ & 2.406 & 0.49 & 3.17 & 0.2 & 40.62 & $<0.0001$ & 36.40 & $<0.0001$ & 17.18 & $<0.0001$ \\
\hline $\begin{array}{l}\text { Claims to know about } \\
\text { the cause of DM }\end{array}$ & 2.72 & 0.43 & 17.06 & $<0.0001$ & 18.91 & $<0.0001$ & 2.75 & 0.09 & 2.14 & 0.34 \\
\hline Chronicity of DM & 14.39 & 0.02 & 17.78 & 0.001 & 27.42 & $<0.0001$ & 8.81 & 0.01 & 23.58 & $<0.0001$ \\
\hline $\begin{array}{l}\text { Type of current } \\
\text { treatment }\end{array}$ & 7.56 & 0.27 & 17.82 & 0.001 & 30.57 & $<0.0001$ & 0.403 & 0.81 & 8.73 & 0.06 \\
\hline $\begin{array}{l}\text { Presence of co-morbidity } \\
\text { or complications }\end{array}$ & 5.01 & 0.17 & 5.76 & 0.05 & 5.59 & 0.06 & 5.44 & 0.02 & 4.85 & 0.08 \\
\hline $\begin{array}{l}\text { History of hospitalization } \\
\text { due to complications } \\
\text { of diabetes during } \\
\text { the past year }\end{array}$ & 10.37 & 0.01 & 12.01 & 0.002 & 23.44 & $<0.0001$ & 4.08 & 0.04 & 13.19 & 0.001 \\
\hline The severity of illness & 27.90 & $<0.0001$ & 11.03 & 0.02 & 16.85 & 0.002 & 16.27 & $<0.0001$ & 17.43 & 0.002 \\
\hline
\end{tabular}

words, the appropriate payment mechanisms have not been designed to support the existing structure. In Kavosi et al.'s study (2018), self-referrals and unnecessary referrals are reported as the most important problems of the referral system in Iran [18].

Based on the findings of this study, the majority of diabetics reported that they initially referred to a physician in the event of illness symptoms, and only a few percentages of patients consulted family members, friends, and relatives. This action can be considered as a positive behavior. Although a substantial percentage of patients reported that they did self-medication initially in the event of disease symptoms, it should be noted that self-medication without doctor consultation may result in drug interactions, unwanted consequences and exacerbation of the disease. In a study by Musinguzi et al., self-medication and access to antihypertensive drugs with or without prescription were common as well as the use of herbal remedies [19]. Dawood et al. reported that $66.7 \%$ of the participants chose to consult the physician when they experienced any health problems, and only $20.9 \%$ do self-medication, and the association between the practice of self-medication and Chinese participants, educated people, people with alone living status and people with more self-care orientation was significant [20]. Dominguez reported that more than half of the diabetic patients sought advice from someone, and the first person they went to was their doctor and $41.2 \%$ of the respondents visited their doctor on a monthly basis, and effective factors for seeking consult were the presence of co-morbidities, perceived effectiveness of treatment, observance of proper diet, exercise, and compliance to treatment [8].

In this study, gender solely had no effect on the health seeking behavior variables, and age was significantly associated with the follow-up pattern only. Older patients are more likely follow-up their treatment in a regular basis. Urban patients were more likely to go to a physician in the event of illness, whilst rural patients were more likely to consult family members, friends and relatives, and do self-medication. This issue can 


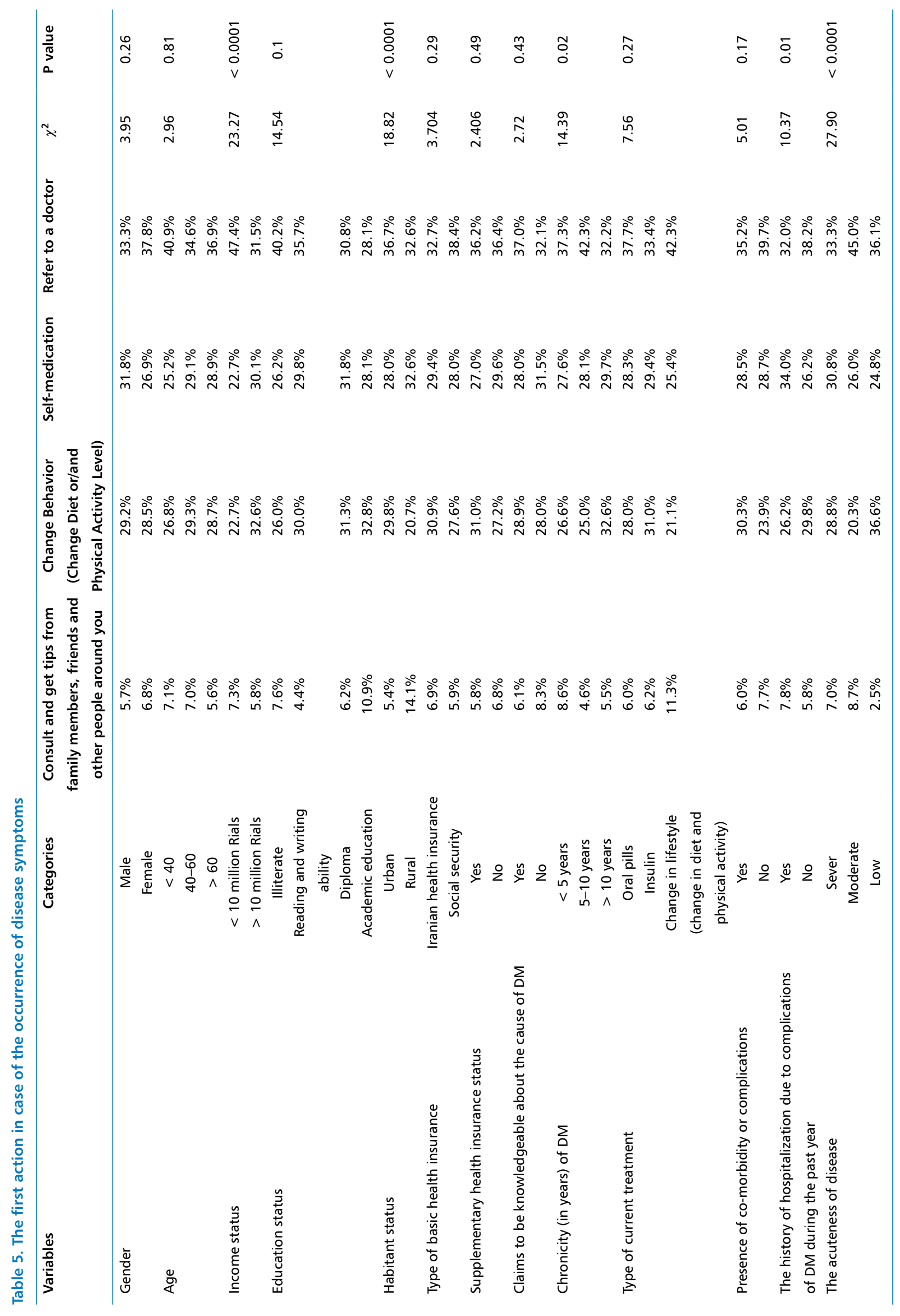




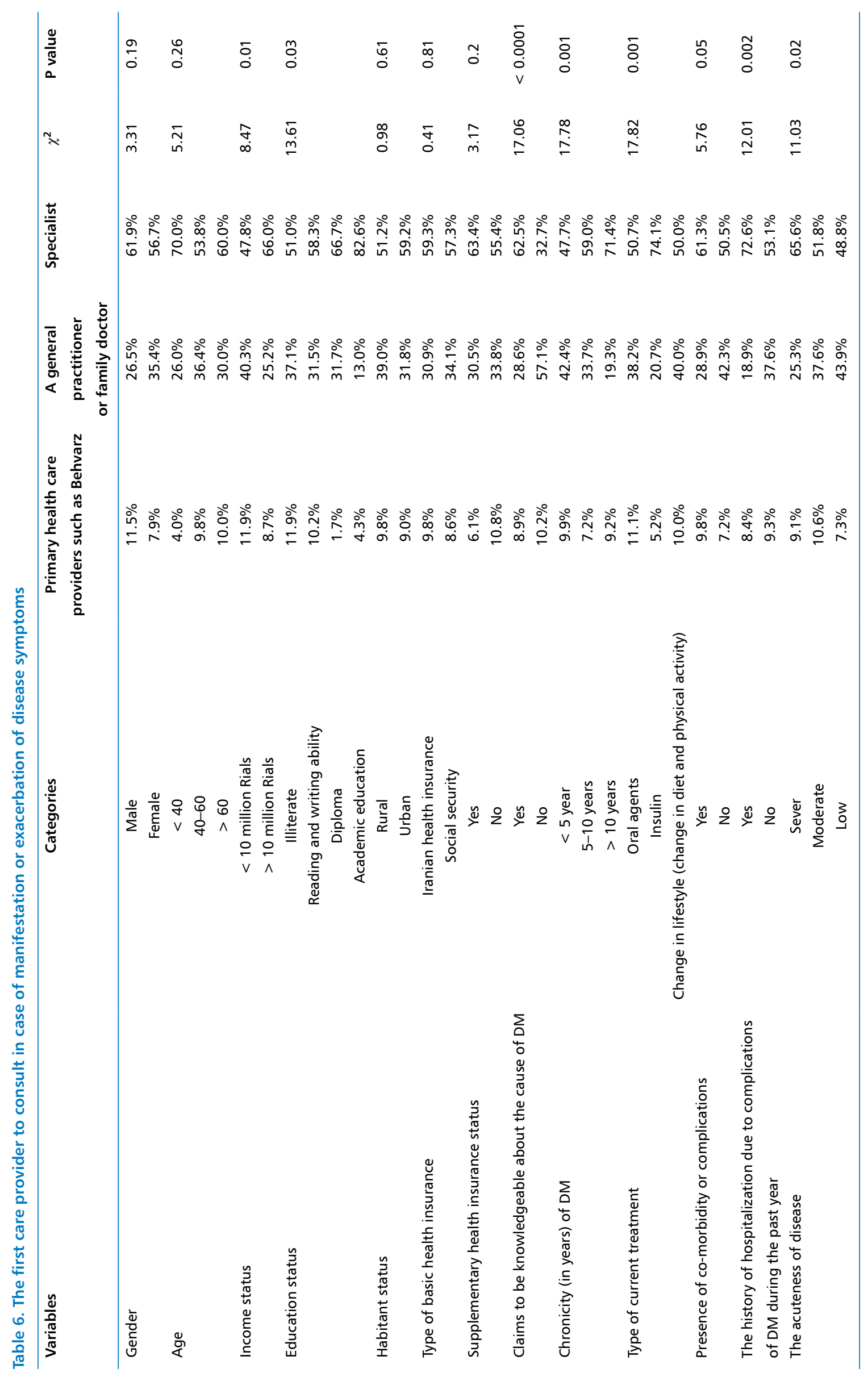


be attributed to easy access to a physician in urban areas. A more percentage of individuals with higher income used behavior change and self-medication in the event of illness symptoms, while those with lower income preferred to go to a physician.

Moreover, more than two-thirds of the patients reported that they referred to their own physician in the event of worsening of symptoms, and only a small percentage changed their own physician. This issue can be regarded as a positive behavior because continuity of care is of paramount importance in diabetes management and this reinforces the patient-physician relationship.

The results showed that the highest percentage of patients referred to the public hospitals and university clinics and approximately one-third of patients reported they referred to the private centers. Patients with higher income and education, patients residing in urban areas and those who were covered by social security and supplementary insurance were more likely to go to private health centers. Private centers provide high-quality hoteling services with a less waiting list but private sector tariffs are high and it is expensive to go to a private health center. So, people who have a better socioeconomic status are more likely to go to the private health centers. Therefore, the cost of private sector services area barrier for poor people to using these services. In Hjelm et al.'s study, men more often turned to private for-profit clinics while females more often used free governmental institutions [1]. In Bhosale and Durgesh's study, only $34.1 \%$ of patients used government health facilities [21].

Also, diabetic patients with a longer history of diabetes were more likely to refer to private centers, while those with a shorter history of diabetes were more likely to refer to primary health care centers. Duration of the disease is considered as an effective factor in the selection of the service provider among these patients. This issue may be due to the severity and complexity of disease in patients with a longer history of diabetes. In Iran, private centers provide more advanced secondary and tertiary services.

Patients without comorbidity, those without a history of hospitalization and those who reported their disease severity as being moderate were more likely to go to private centers. Patients whose usual treatment was a lifestyle change (change of diet and physical activity level) were more likely to go to primary health centers, whilst individuals who were under insulin therapy were more likely to refer to private centers. In addition, patients who were under insulin therapy had a more severe and complex condition, and these patients refer more to private and specialized centers.
Hence, disease severity is an important factor in the type of individuals' behavior while choosing a service provider. In a study by Inche et al., appropriate healthseeking behavior was significantly associated with age, presence of co-morbidity, family history of diabetes, distance from health facilities, perceived family support, as well as the history of early treatment seeking at diagnosis and duration of disease [22].

Most people visited a physician every three months on a regular basis even if they were asymptomatic. In Iran, after the implementation of the Health System Evolution Plan (HSEP) reform and IraPEN, primary health centers are obliged to monitor and visit diabetic patients every three months. Therefore, policies, regulations and health reforms affect health care seeking behaviors directly and indirectly. In Dominguez's study, $41.2 \%$ of the diabetic patients visited their doctor on a monthly basis [8]. In our study, $11.9 \%$ and $51.6 \%$ of patients visited their doctor monthly and every three months, respectively.

In regard to the follow-up pattern, 78.85 of patients reported they referred to a physician on a regular basis and $59.9 \%$ of patients followed up their treatment process on a regular basis. A study in 2017 showed that $82.3 \%$ of patients with diabetes were taking treatment regularly [21]. In Makinga and Beke's study, 95\% of the patients preferred to consult their physicians on a regular basis [23].

Moreover, older patients, patients with social security coverage, patients with supplementary insurance coverage and patients residing in urban areas were more likely to refer to health care providers on a regular basis. Patients who are covered by social security insurance and supplementary insurance, in addition to having better socioeconomic status, pay a smaller amount of franchise when they refer to the physician. So, these individuals are more likely to go to a physician on a regular basis. In the case of the urban area residents, it can be attributed to better access to the physician. According to Yinzi Jin et al.'s study, the positive influence of increasing the number of physicians available to DM patients in rural and western areas was greater than that for urban and eastern DM patients in China [24]. Musinguzi et al.'s study showed that factors influencing HSB are related to health systems and the patient socioeconomic and structural environment [19].

In this study, the majority of the patients received the required information for the management of their disease from their physician. This can be considered as a positive behavior because they prefer to receive the required information from a well-informed source. Also, a considerable proportion of patients consulted the family members and friends. Furthermore, given that most of the 
patients in this study were elderly and had a low education level, just a few proportions of them used the electronic database, blogs, websites, health portals, mobile applications, and social networks. Also, Radio and TV programs and Diabetes Associations failed to play their crucial role in informing diabetic patients. A study by Kuske et al. showed that the Internet and health care professionals were the most frequently reported sources [30].

\section{Conclusion}

Most of the diabetics often did not follow the official structure of health care providers to manage their illness, and despite the referral system and family practitioner program, more than half of the patients went directly to the specialist physician's office. Factors related to the patients (income and education status), disease characteristics (disease severity, chronicity of DM and the history of hospitalization due to DM) and health care systems (type of basic insurance and supplementary insurance status) affect the health care seeking behaviors.

\section{Conflict of interest}

The authors have no conflicts of interest to declare.

\section{Ethics approval}

Ethical approval was obtained from the Research Deputy of Tabriz University of Medical Sciences (Ref. No. IR. TBZMED. REC.1397.166).

\section{Acknowledgements}

We would like to thank the Student Research Committee, Tabriz University of Medical Sciences for funding this study (Grant No; IR. TBZMED. REC. 60252). Also, we wish to thank the educational hospitals, diabetes clinics and primary health care centers affiliated to Tabriz University of Medical Sciences and private endocrinologist offices for collaborating with the authors in conducting data collection.

\section{REFERENCES}

1. Hjelm K, Atwine F. Health care seeking behaviour among persons with diabetes in Uganda: an interview study. BMC Int Health Hum Rights. 2011; 11: 11, doi: 10.1186/1472-698X-11-11, indexed in Pubmed: 21943099.

2. Conca T, Saint-Pierre C, Herskovic V, et al. Multidisciplinary collaboration in the treatment of patients with type 2 diabetes in primary care: analysis using process mining. J Med Internet Res. 2018; 20(4): e127, doi: 10.2196/jmir.8884, indexed in Pubmed: 29636315.

3. Gucciardi E, Espin S, Morganti A, et al. Exploring interprofessional collaboration during the integration of diabetes teams into primary care. BMC Fam Pract. 2016; 17: 12, doi: 10.1186/ s12875-016-0407-1, indexed in Pubmed: 26831500.

4. Lim SS, Gaziano TA, Gakidou E, et al. Prevention of cardiovascular disease in high-risk individuals in low-income and middle-income countries: health effects and costs. Lancet. 2007; 370(9604): 2054-2062, doi: 10.1016/S0140-6736(07)61699-7, indexed in Pubmed: 18063025.

5. Olenja J. Health seeking behaviour in context. East Afr Med J. 2003; 80(2): 61-62, doi: 10.4314/eamj.v80i2.8689, indexed in Pubmed: 16167716.

6. Ali M, de Muynck A. Illness incidence and health seeking behaviour among street children in Rawalpindi and Islamabad, Pakistan - a qualitative study. Child Care Health Dev. 2005; 31(5): 525-532, doi: 10.1111/j.1365-2214.2005.00545.x, indexed in Pubmed: 16101647.

7. Gazmararian JA, Ziemer DC, Barnes C. Perception of barriers to self-care management among diabetic patients. Diabetes Educ. 2009; 35(5): 778-788, doi: 10.1177/0145721709338527, indexed in Pubmed: 19556552.

8. Dominguez RJ. Health-seeking behavior of patients with diabetes mellitus in Baguio City. 2010.

9. Gentili PMA, Grieco R, Santini A. Influence of patients' representations and beliefs about diabetes and its treatment on their adherence to therapy. Diabetes Nutrition and Metabolism. 2001; 14(3): 140-152.

10. Espinosa P, Espinosa M. Health-Seeking behavior and quality of life of patients with diabetes mellitus in Ioilo, Philippines. International Journal of Bio-Science and Bio-Technology. 2017; 9(1): 103-112, doi: 10.14257/ijbsbt.2017.9.1.08.

11. Mayxay M, Hansana V, Sengphilom B, et al. Respiratory illness healthcare-seeking behavior assessment in the Lao People's Democratic Republic (Laos). BMC Public Health. 2013; 13: 444, doi: 10.1186/1471-2458-13-444, indexed in Pubmed: 23642240.

12. Nimesh VV, Halder A, Mitra A, et al. Patterns of healthcare seeking behavior among persons with diabetes in Central India: A mixed method study. J Family Med Prim Care. 2019; 8(2): 677-683, doi: 10.4103/jfmpc.jfmpc_433_18, indexed in Pubmed: 30984694.

13. Spikmans FJM, Brug J, Doven MMB, et al. Why do diabetic patients not attend appointments with their dietitian? J Hum Nutr Diet. 2003; 16(3): 151-158, doi: 10.1046/j.1365-277x.2003.00435.x, indexed in Pubmed: 12753108.

14. Venmans LM, Gorter KJ, Hak E, et al. Short-term effects of an educational program on health-seeking behavior for infections in patients with type 2 diabetes: a randomized controlled intervention trial in primary care. Diabetes Care. 2008; 31(3): 402-407, doi: 10.2337/dc07-0744, indexed in Pubmed: 18056887.

15. Mehrdad R. Health system in Iran. JMAJ. 2009; 52(1): 69-73.

16. Verulava T. Health care system in the Islamic Republic of Iran. Insurance, Health Policy \& Management. 2006.

17. Rasoulynejad S. Study of self-referral factors in the three-level healthcare delivery system, Kashan, Iran, 2000. Rural Remote Health. 2004; 4(4): 237, indexed in Pubmed: 15887984.

18. Kavosi Z, Siavashi EA. Study of the Performance of Referral System in Urban Family Physician Program in Fars Province, Iran. Journal of Health Management and Informatics. 2018; 5(3): 88-95.

19. Musinguzi G, Anthierens $S$, Nuwaha $F$, et al. Factors Influencing Compliance and Health Seeking Behaviour for Hypertension in Mukono and Buikwe in Uganda: A Qualitative Study. Int J Hypertens. 2018; 2018: 8307591, doi: 10.1155/2018/8307591, indexed in Pubmed: 29854433.

20. Dawood OT, Hassali MA, Saleem F, et al. Assessment of health seeking behaviour and self-medication among general public in the state of Penang, Malaysia. Pharm Pract (Granada). 2017; 15(3): 991, doi: 10.18549/PharmPract.2017.03.991, indexed in Pubmed: 28943981.

21. Bhosale S, Pawar A, K D. Healthcare-seeking behavior among diabetic patients in Kozhikode, Kerala. International Journal of Medical Science and Public Health. 2017; 6(10): 1524-1528, doi: 10.5455/ijmsph.2017.0721325082017.

22. Abidin SI, Sutan R, Shamsuddin K. Prevalence and determinants of appropriate health seeking behaviour among known diabetics: results from a community-based survey. Advances in Epidemiology. 2014; 2014: 1-7, doi: 10.1155/2014/793286. 
23. Makinga PN, Beke A. A cross-sectional survey on the lifestyle and health-seeking behaviour of Basotho patients with diabetes. South African Family Practice. 2014; 55(2): 190-195, doi: 10.1080/20786204.2013.10874332.

24. Jin Y, Zhu W, Yuan B, et al. Impact of health workforce availability on health care seeking behavior of patients with diabetes mellitus in China. Int J Equity Health. 2017; 16(1): 80, doi: 10.1186/ s12939-017-0576-0, indexed in Pubmed: 28666449.

25. Egede $L E, Y e X$, Zheng $D$, et al. The prevalence and pattern of complementary and alternative medicine use in individuals with diabetes. Diabetes Care. 2002; 25(2): 324-329, doi: 10.2337/ diacare.25.2.324, indexed in Pubmed: 11815504.

26. Hasan SS, Ahmed SI, Bukhari NI, et al. Use of complementary and alternative medicine among patients with chronic diseases at outpatient clinics. Complement Ther Clin Pract. 2009; 15(3): 152-157, doi: 10.1016/j.ctcp.2009.02.003, indexed in Pubmed: 19595416.
27. Kim J, Chan MM. Factors influencing preferences for alternative medicine by Korean Americans. Am J Chin Med. 2004; 32(2): 321-329, doi: 10.1142/S0192415X04001977, indexed in Pubmed: 15315269.

28. Lui CW, Dower Jo, Donald M, et al. Patterns and Determinants of Complementary and Alternative Medicine Practitioner Use among Adults with Diabetes in Queensland, Australia. Evid Based Complement Alternat Med. 2012; 2012: 659419, doi: 10.1155/2012/659419, indexed in Pubmed: 22919416.

29. Sethi A, Srivastava S, Madhu SV. Prevalence and pattern of use of indigenous medicines in diabetic patients attending a tertiary care centre. J Indian Med Assoc. 2011; 109(7): 469-471, indexed in Pubmed: 22315837.

30. Kuske S, Schiereck T, Grobosch S, et al. Diabetes-related information-seeking behaviour: a systematic review. Syst Rev. 2017; 6(1): 212, doi: 10.1186/s13643-017-0602-8, indexed in Pubmed: 29065919. 